\title{
Influence of Watering Solution and Phenotype on the Growth of in Vitro Propagated Pineapple (Smooth Cayenne Cultivar) Plantlets during Acclimatization
}

\author{
Arnaud Agbidinoukoun ${ }^{1}$, Gaston C. Ouikoun ${ }^{2}$, Toussaint Mikpon², Gatien T. Kamade ${ }^{1}$, \\ Bienvenu T. Badou1, Richmy C. B. Aïsso², Serge S. Houedjissin', Jerome A. Houngue1, \\ René C. Dossoukpevi1,3, Corneille Ahanhanzo ${ }^{1,3}$
}

${ }^{1}$ Central Laboratory of Plant Biotechnology and Plant Breeding, Faculty of Sciences and Techniques, University of Abomey-Calavi, Cotonou, Benin

${ }^{2}$ National Institute of Agricultural Research of Benin, Cotonou, Benin

${ }^{3}$ Benin Center of Scientific Research, Technology and Innovation, Cotonou, Benin

Email: ^arnaudag2002@yahoo.fr

How to cite this paper: Agbidinoukoun, A., Ouikoun, G.C., Mikpon, T., Kamade, G.T., Badou, B.T., Aïsso, R.C.B., Houedjissin, S.S., Houngue, J.A., Dossoukpevi, R.C. and Ahanhanzo, C. (2021) Influence of Watering Solution and Phenotype on the Growth of in Vitro Propagated Pineapple (Smooth Cayenne Cultivar) Plantlets during Acclimatization. Agricultural Sciences, $12,1215-1230$.

https://doi.org/10.4236/as.2021.1211077

Received: June 21, 2021

Accepted: November 7, 2021

Published: November 10, 2021

Copyright $\odot 2021$ by author(s) and Scientific Research Publishing Inc. This work is licensed under the Creative Commons Attribution International License (CC BY 4.0).

http://creativecommons.org/licenses/by/4.0/ (c) (i) Open Access

\begin{abstract}
Pineapple is the first fruit crop cultivated in south Benin that greatly contributes for food and nutritional security and farmers' income. But the lack of homogenous planting material constitutes the major constraint for improving pineapple yield. In vitro micropropagation is now used in the production of homogenous and free disease planting materials of pineapple. However, the acclimatization to natural condition of pineapple plantlets is an important step in planting material production of this crop. Here, we determined the intrinsic and extrinsic factors which influence the behavior of plantlets during the acclimatization process. For this purpose, plantlets from different categories were selected, trimmed and planted on a horticultural substrate made up of potting soil, white sawdust and compost previously sterilized. The plantlets were then incubated in under acclimatization greenhouse with average temperature of $29^{\circ} \mathrm{C}$ and $70.2 \%$ of humidity. A batch of plantlets was subjected to two different watering solutions: Shive and Robbins solution and NPK 14-6-5 foliar fertilizer. The results obtained initially showed high rate (100\%) of survival and growth of the plantlets watered with Shive and Robbins solution against $50 \%$ of the plantlets watered with the foliar fertilizer solution. In addition, the plantlets with spread pores exhibiting the characteristics of which the number of leaves varies between 9 and 11, the weight between 1.2 and 1.5 $\mathrm{g}$, the size of 4.5 to $5.5 \mathrm{~cm}$, and a good junction between the aerial part and
\end{abstract}


the root system were those which were successfully grown in acclimatization phase under greenhouse, unlike plantlets with erected pores having lower success rate. This study goes a long way in providing good procedures of acclimatization of homogenous and free disease planting material of pineapple to the famers.

\section{Keywords}

Ananas comosus var. comosus, Plantlets Morphology, Nutrient Supply, Pineapple Acclimatization, In Vitro Tissue Culture

\section{Introduction}

Pineapple (Ananas comosus var. comosus) is one of the main tropical fruits traded internationally with the world production exceeding 15 million tons since 2005 [1]. Global pineapple production has increased from 21.5 million tons in 2011 to 27.92 tons in 2019. The pineapple would thus occupy the eleventh place among the cultivated fruits according to FAO statistics [2]. In West Africa, pineapple is the second most important tropical fruit in terms of production, after banana [3]. In Benin, pineapple is the first fruit crop in South Benin, particularly in Atlantique region where it is grown by $70 \%$ of farmers [4]. Pineapple occupies an important place among the thirteen promising crops to be promoted in Benin. Thus, pineapple production has increased dramatically over the last ten years. However, its production is subjected to many constraints among the organizational difficulties that did not favor the synergy of marketing system towards the European Union [5]. The unproductive technical itineraries and the heterogeneity of the fruits [6] [7] [8] are the main constraint of pineapple production. Tossou et al., [9] showed that $80 \%$ of the fruits produced were downgraded due to their heterogeneity. Unavailability of planting material is a major constraint for intensifying the production of pineapple in Benin [10]. Tissue culture technique allowed to produce a large number of healthy and homogeneous planting materials [11] [12] [13] [14] [15]. One of the techniques used to obtain the plantlets is micropropagation [16] [17]. The plantlets produced in the laboratory request a progressive adaptation to the natural environment. Hence, it is important to search the strategies to improve the acclimatization protocol of pineapple in vitro plantlets [18] [19]. The ultimate stage of acclimatization, which is poorly controlled, can lead to high mortality rates in pineapple [20]. Several strategies have been employed to promote faster and more efficient acclimatization of pineapple plants, including the use of nitrogen-fixing microorganisms [21] and modifications in light supply [22], irrigation and fertilization [23]. However, the acclimatization of pineapple plantlets requests an improved technical itinerary that can ensure a high rate of plantlet survival during the acclimatization process. The present study was carried out in order to establish 
an acclimatization technical itinerary that can reduce the mortality rate. It is aimed to improve the viability rate of pineapple plantlets during the acclimatization process by 1 ) testing two different types of watering solutions on the survival and growth of plantlets and 2) evaluating the influence of the plantlets morphology on survival response during acclimatization.

\section{Material and Methods}

\subsection{Plant Material}

The plant materiel is composed by Smooth Cayenne cultivar plantlets provided at Central Laboratory of Plant Biotechnology and Plant Breeding of the University of Abomey-Calavi. The plantlets were grown and rooted on modified $\mathrm{Mu}$ rashige and Skoog medium [24] prior to transferring at the Agricultural Research Center in Niaouli locality (South Benin).

\subsection{Methods}

\subsubsection{Substrate Preparation}

The substrate used was a mixture of compost, white sawdust and potting soil. Each element was first sieved on $1 \mathrm{~mm}^{2}$ mesh sieve with a $1 \mathrm{~cm}^{2}$ wider mesh to avoid that the weight was not high enough on the sieve with the smallest mesh (Figure 1). After sieving, each component was weighed on an electric balance. Compost, potting soil, and white sawdust were taken out respectively according to the 2-1-1 formula. The mix was poured into a metal drum after being mixed properly with water and sterilized at $200^{\circ} \mathrm{C}$ with firewood for $12 \mathrm{~h}$. During the entire sterilization process, the drum remained hermetically sealed and cooling down before being filled into the sockets.

\subsubsection{Conditioning of Plantlets}

After receiving the plantlets, the bowl were firstly opened and then rinsed. The technique of rinsing is consisted of washing the plantlets in three (03) different basins each containing water (Figure 2). The dead leaves, debris and medium were removed from the plantlets. The fact of getting rid of the medium is very important, the medium was rich in sugar and mineral substances, bacteria or other microorganisms residing in the transplanting medium could compete with the young seedling and cause its death.
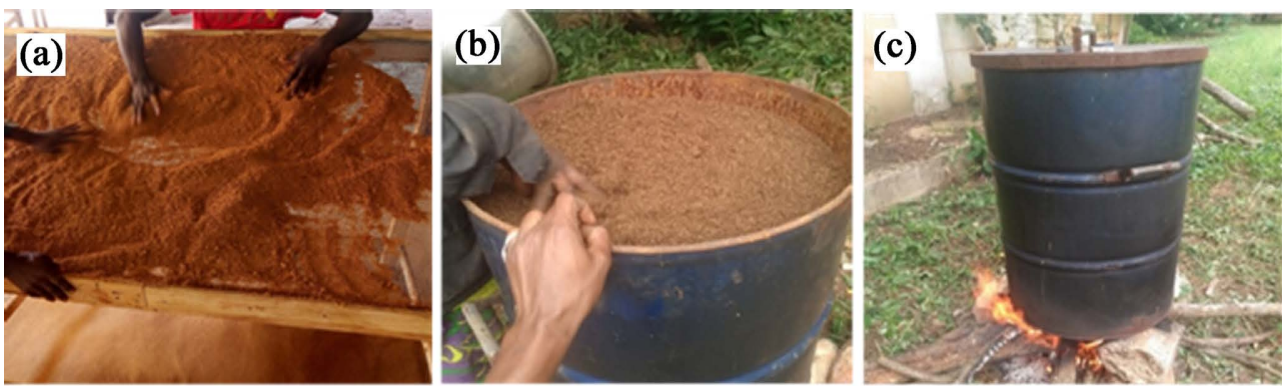

Figure 1. (a) Sieving of substrates constituent; (b) and (c) Sterilization of substrate. 


\subsubsection{Calibration and Transplanting in Greenhouse}

Under greenhouse, the plantlets were manually calibrated. Six (06) categories of plantlets were emerged from this calibration (Figure 3). After the calibration step, the plantlets were transplanted into the sockets. For this purpose, the substrate was first sprayed with Shive and Robbins nutrient solution [25]. Thereafter, the plantation was then carried out by lightly covered the root part of the plantlets with substrate. The honeycombed trays containing the plantlets were placed on the shelves. One set of plantlets were watered daily with Shive and Robbins nutrient solution and the second set with NPK 14-6-5 foliar fertilizer. In
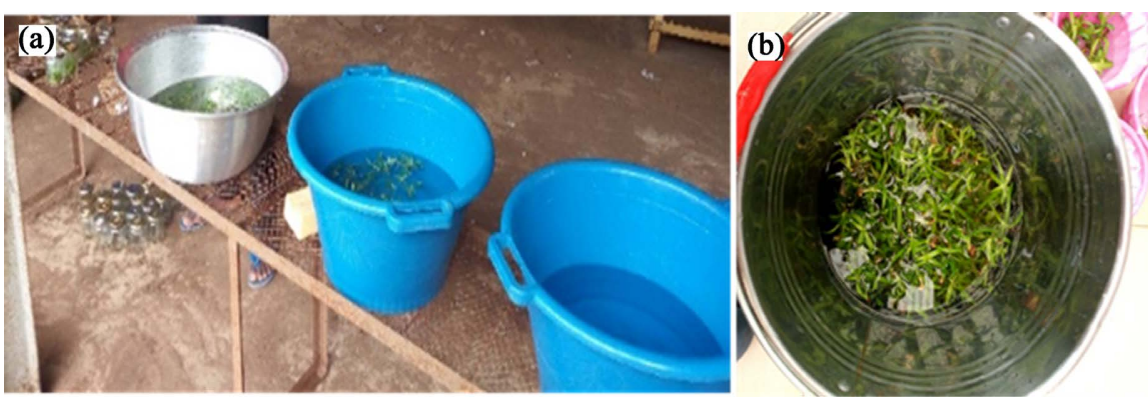

Figure 2. Pineapple plantlets rinsing; (a) beginning, (b) End.
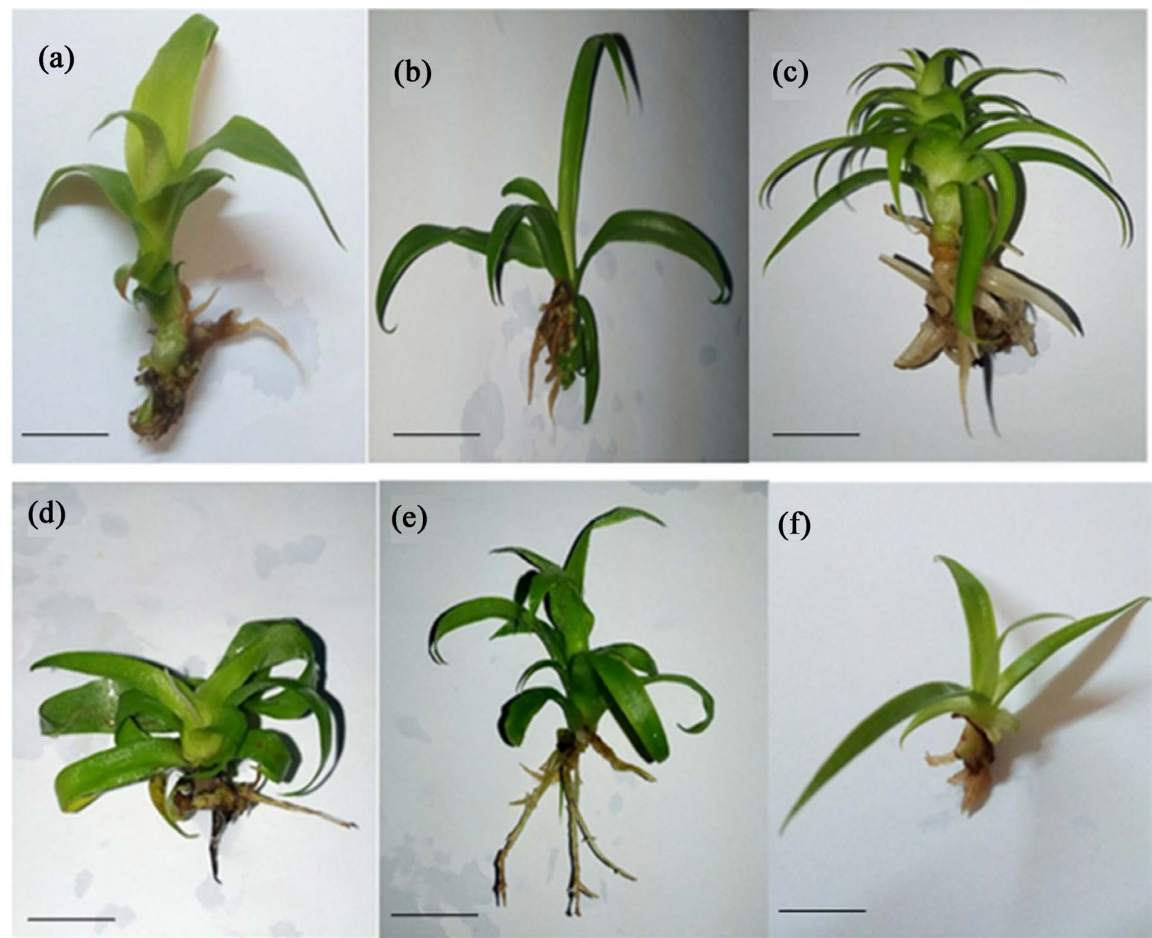

Figure 3. Categories of plantlets. (a) Category of vigorous plantlets (size $\geq 4.2 \mathrm{~cm}$ ) with large pores and well-open leaves; (b) Category of vigorous plantlets (size $\geq 4.2 \mathrm{~cm}$ ) with large pores and semi-open leaves; (c) Category of vigorous plantlets (size $\geq 4.2 \mathrm{~cm}$ ) with erected pores and semi-open leaves; (d) Category of no vigorous plantlets (size: 2.2 - 4.1 $\mathrm{cm}$ ) with exhibited pores and well-open leaves; (e) Category of vigorous plantlets (size $\geq$ $4.2 \mathrm{~cm}$ ) with exhibited pores and semi-open leaves; (f) Category of small plantlets (size $\leq$ $2.1 \mathrm{~cm}$ ) with exhibited pores and semi-open leaves. 
order to prevent fungal attack, the application of a broad-spectrum fungicide (Mancozeb) was made twenty days after transplanting. The temperature and hygrometry were collected three (03) times a day: $07 \mathrm{~h}, 12 \mathrm{~h}$ and $17 \mathrm{~h}$ using a hygrometer.

\subsubsection{Transfer of Plantlets from Greenhouse to Shadehouse}

Before transferring the plantlets to the shade, the substrate must first be potted and processed. The substrate used consists only of potting soil previously treated with mancozeb fungal attack prevention. The substrate was then loaded into polyethylene bags and moved to the shadehouse. The substrate was first watered before the transplantation of plantlets into the pots (Figure 4).

\subsubsection{Experimental Design}

For the study, 144 plantlets were selected of which 72 were used for spraying solution study. Completely random block was used in the experiment. For watering solution test, twelve (12) exhibited pore plantlets of different sizes were used per treatment with three (03) replicates. During the first month, one lot was treated with the Shive and Robbins solution and the second lot with the foliar fertilizer solution. By the second month, both lots were all treated with Shive and Robbins's solution. For the test relating to the different categories tested, 12 plantlets per category were used.

\subsubsection{Parameters and Data Analysis}

Data relative to number of survival plantlets, the foliar emission rate, number of root, survival in different category of plantlets, the gain in size and weight of plantlets, and number of roots were collected from different categories of plantlets. The number of survival plantlets is a difference between the initiated plantlets and dead plantlets whereas the foliar emission rate difference between the initial leaves of plantlets and final leaves number of the plantlets. The number of roots in each plantlets of each category at the beginning was subtracted from the total number of same category while the gain in size and weight of plantlets is the difference between the final size and weight of the plantlets with the initial. Data collected from the experiment were analyzed with STATISTICA 6 software. The analysis of variance (ANOVA) was mainly performed to determine significant differences between the different categories of plantlets according to the
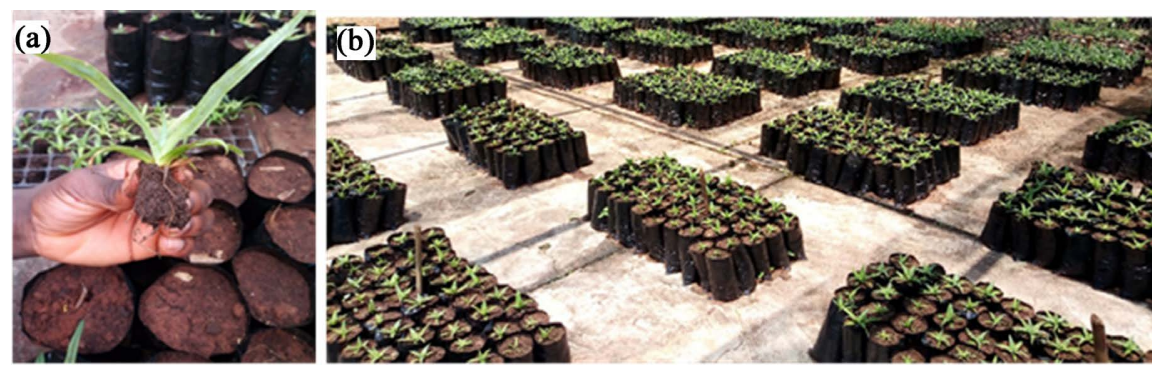

Figure 4. Transplantation of plantlets into shaded pots. (a) Beginning, (b) End. 
different parameters number of roots formed, height gain and weight gain in the different categories of plantlets tested. Fisher's LSD test was performed in order to find out where the significant differences between the different categories lie for these studied parameters. Then, the Chi-square test was used to show the difference in significance between the survival rate of the different categories of plantlets, and finally the fish regression test was used to know the time effect, the category effect and the effect of time* category interaction on the foliar emission rate. The graphs and tables were constructed using the Excel 2013 workbook and the STATISTICA 6 software.

\section{Results}

\subsection{Effects of Watering Solution on the Plantlets Survival}

The response of plantlets varied with the two watering solutions in the rate of foliar emission $(\mathrm{P}<0.0001)$ and the time of emission $(\mathrm{P}=0.027)$. After 60 -days watering, the two sets of plantlets respectively spayed with the Shive and Robbins solution and foliar fertilizer solution, significant mortality (14) was noted in the set watered with the foliar fertilizer solution while no mortality was recorded in the set watered with the Shive and Robbins solution (Figure 5). The plantlets sprayed with Shive and Robbins nutrient solution presented good physiological aspect (Figure 6).

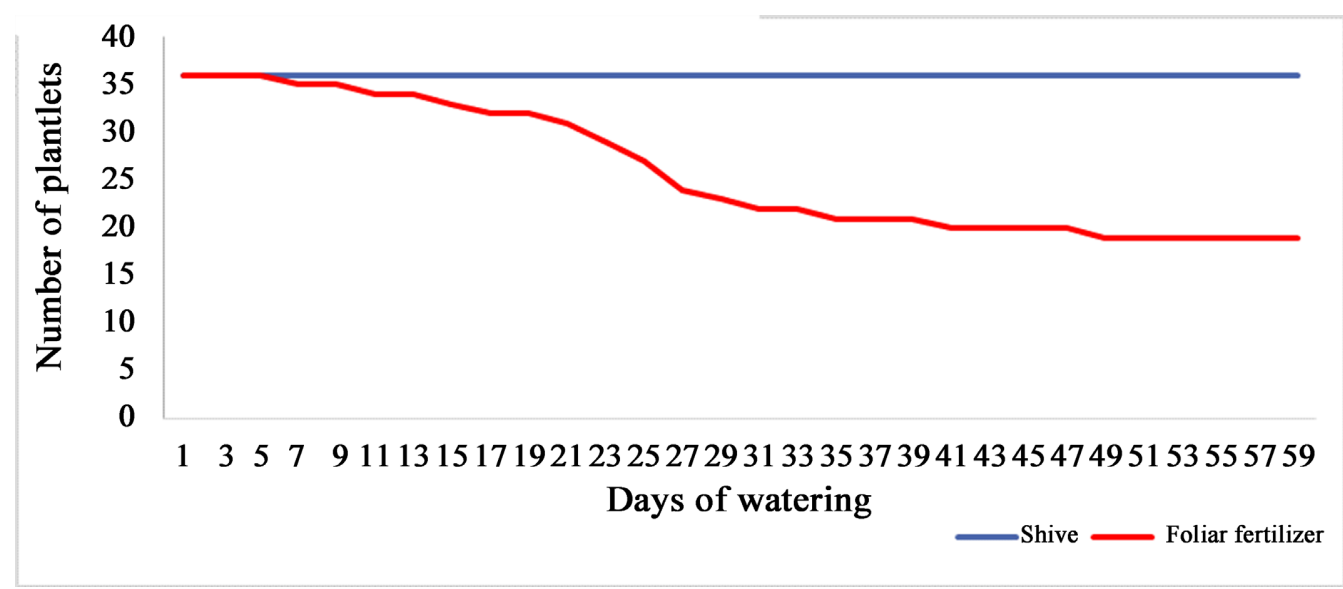

Figure 5. Number of plantlets mortality per days during the application of watering solutions.
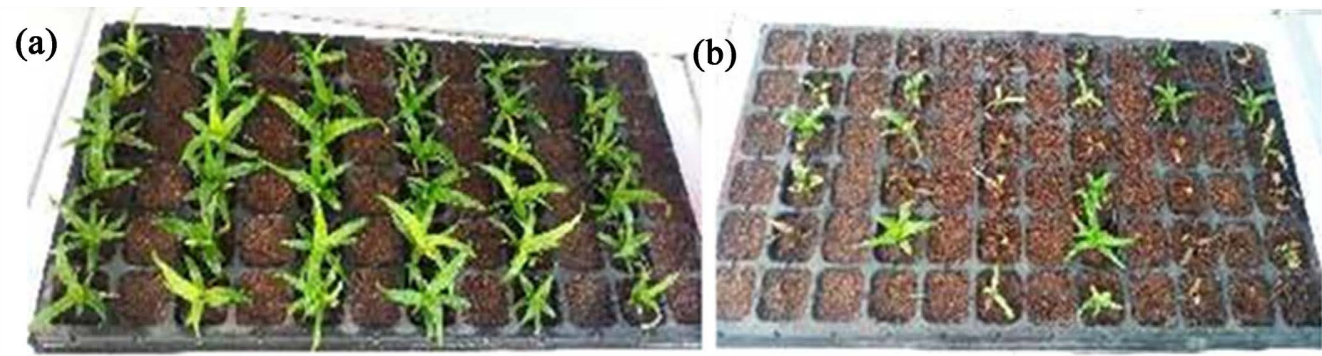

Figure 6. Plantlets sprayed with Shive and Robbins nutrient solution and foliar fertilizer. (a) Batch sprayed with Shive and Robbins solution; (b) batch sprayed with foliar fertilizer. 


\subsection{Foliar Emission Rate of the Different Categories after Calibration}

There were a significant different $(\mathrm{P}<0.0001)$ in the rate of foliar emission of different category of plantlets and the time of emission (Table 1). These two factors taken together also significantly $(\mathrm{P}<0.0001)$ influenced the foliar emission rate (Table 1). After calibration, the 06 categories of plantlets evolved more or less differently when considering the foliar emission rate. The results of the foliar emission rate of each category were presented in Table 2 . The category of vigorous plantlets with exhibited pores and semi-open leaves showed the best foliar emission rate (1.22 leaves/week after the adaptation phase: $(\mathrm{d} 0$ - d31)). In contrast, the category of vigorous plantlets with erected pores and semi-open leaves presented the lowest rate of foliar emission. The greatest loss was recorded during the adaptation phase $(\mathrm{d} 0-\mathrm{d} 31)$. Leave losses was estimated at 0.35 leaves/week after 31 days (Table 2).

\subsection{Survival Rates of the Different Categories of Plantlets Obtained after Calibration}

There was a significant difference $(\mathrm{P}<0.0001)$ in the response of the different categories of plantlets with respect to survival rates (Table 3 ). Indeed, by spending sixty (60) days under the acclimatization greenhouse, the category A, C, and D plantlets gave $100 \%$ of survival rate whereas the category $\mathrm{E}$ and $\mathrm{F}$, gave respectively $91.66 \%$ and $75 \%$ of survival rates (Figure 7 ).

Table 1. Fish regression on the rate of foliar emission.

\begin{tabular}{cccccc}
\hline Source & DDL & Sum of squares & Average of squares & F & Pr $>$ F \\
\hline Categories & 5 & 1971.3667 & 94.2733 & 36.0333 & $<0.0001$ \\
Time & 4 & 121.6278 & 30.4069 & 2.7789 & 0.0270 \\
Categories * Time & 20 & 871.7722 & 43.5886 & 3.9836 & $<0.0001$ \\
\hline
\end{tabular}

Table 2. Leaf emission rate of each category with the time.

\begin{tabular}{ccccc}
\hline Categories of plantlets & Day 31 & Day 38 & Day 46 & Day 52 \\
\hline A & 1.75 & 1.00 & 0.75 & 1.17 \\
B & 2.17 & 1.67 & 0.75 & 1.25 \\
C & -4.93 & -0.36 & -0.34 & -0.36 \\
D & 1.69 & 0.55 & 0.18 & 0.64 \\
E & 1.67 & 0.67 & 0.50 & 0.58 \\
F & 2.02 & 0.50 & 1.01 & 0.56 \\
\hline
\end{tabular}

Table 3. Chi-square test between the survival rates of the different categories of plantlets.

\begin{tabular}{cccccc}
\hline Source & DDL & $\mathrm{Chi}^{2}$ (Wald) & $\mathrm{Pr}>$ Wald & $\mathrm{Chi}^{2}$ (LR) & $\mathrm{Pr}>\mathrm{LR}$ \\
\hline Cat & 5 & 768.447432 & $<0.0001$ & 16.2336508 & $<0.0001$ \\
\hline
\end{tabular}




\subsection{Number of Roots Formed in the Different Categories of Plantlets}

Significant difference $(\mathrm{P}=0.0000)$ between categories of plantlets regarding the number of roots were noted (Table 4). The development of the root system in the categories $\mathrm{A}, \mathrm{C}$ and $\mathrm{E}$ did not differ significantly to each other. The categories $\mathrm{A}, \mathrm{C}, \mathrm{D}$, and $\mathrm{E}$ showed a formation of new roots while the categories $\mathrm{B}$ and $\mathrm{E}$ did not formed new roots. The category $\mathrm{D}$ showed the best rate of root formation with about 6 roots on average. The categories A, C and $\mathrm{E}$ had almost the same rate of root formation with about 2 roots on average (Figure 8).

\subsection{Gain in Size in the Different Categories of Plantlets}

The length of plantlets in the acclimatization phase depended significantly $(\mathrm{P}=$

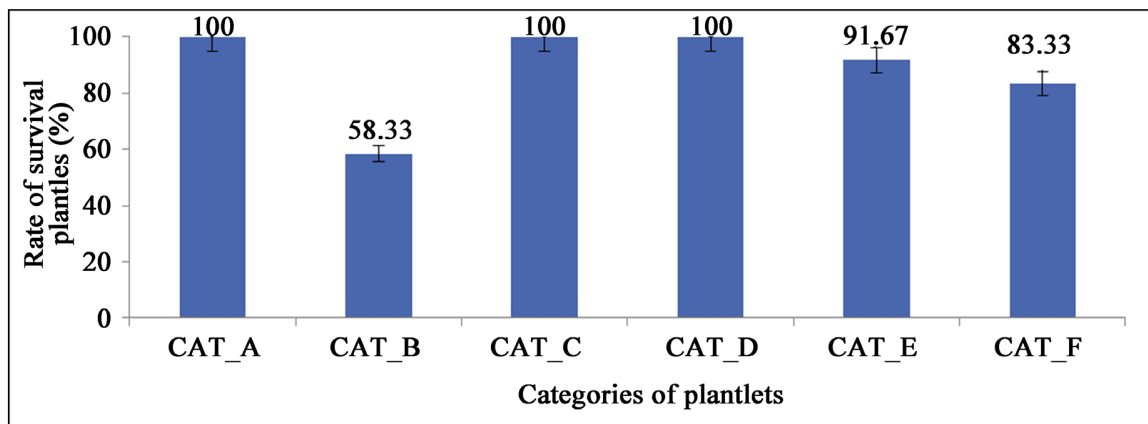

CAT_1: Category of vigorous plantlets (size $\geq 4.2 \mathrm{~cm}$ ) with exhibited pores and well-open leaves; CAT_2: Category of vigorous plantlets (size $\geq 4.2 \mathrm{~cm}$ ) with exhibited pores and semi-open leaves; CAT_3: Category of vigorous plantlets (size $\geq 4.2 \mathrm{~cm}$ ) with erected pores and semi-open leaves; CAT_4: Category of no vigorous plantlets (size: $2.2-4.1 \mathrm{~cm}$ ) with exhibited pores and well-open leaves; CAT_5: Category of vigorous plantlets (size $\geq$ $4.2 \mathrm{~cm}$ ) with exhibited pores and semi-open leaves; CAT_6: Category of small plantlets $($ size $\leq 2.1 \mathrm{~cm})$ with exhibited pores and semi-open leaves.

Figure 7. Survival rate of plantlets according to plantlets categories.

Table 4. Fisher's LSD test showing significant differences between categories for root system development.

LSD test; difference variable (Probabilities for Post Hockey Tests)

Error: $\mathrm{MC}$ Inter $=5.0076, \mathrm{dl}=66.000$

\begin{tabular}{lcccccc}
\hline Categories & $\{\mathrm{A}\}$ & $\{\mathrm{B}\}$ & $\{\mathrm{C}\}$ & $\{\mathrm{D}\}$ & $\{\mathrm{E}\}$ & $\{\mathrm{F}\}$ \\
& $\mathbf{2 . 0 0 0 0}$ & $-\mathbf{1 . 0 0 0}$ & $\mathbf{1 . 7 5 0 0}$ & $\mathbf{5 . 8 3 3 3}$ & $\mathbf{1 . 8 3 3 3}$ & $-\mathbf{0 . 4 1 6 7}$ \\
\hline CAT_A & & 0.002 & 0.785 & 0.000 & 0.856 & 0.010 \\
CAT_B & 0.002 & & 0.004 & 0.000 & 0.003 & 0.525 \\
CAT_C & 0.785 & 0.004 & & 0.000 & 0.928 & 0.021 \\
CAT_D & 0.000 & 0.000 & 0.000 & & 0.000 & 0.000 \\
CAT_E & 0.856 & 0.003 & 0.928 & 0.000 & & 0.016 \\
CAT_F & 0.010 & 0.525 & 0.021 & 0.000 & 0.016 & \\
\hline
\end{tabular}




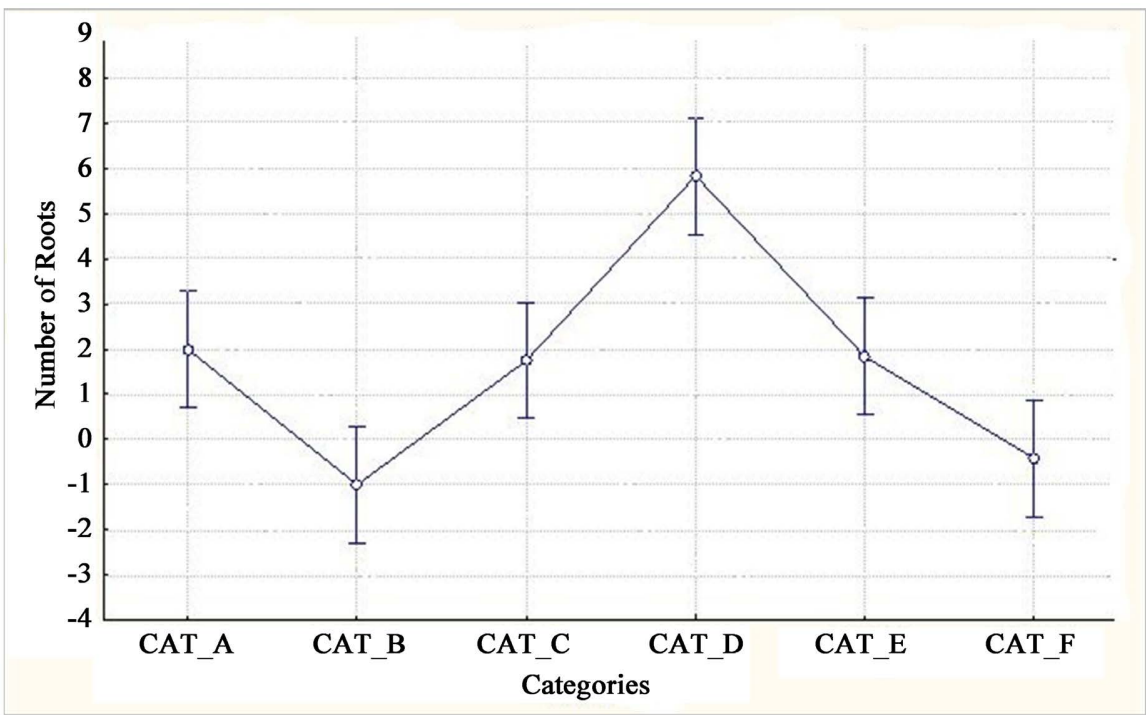

Categories; Avg. Least squares; Current effect: F (5.66) = 13.879, p = 0.00000; Effective decomposition of the hypothesis; the vertical bars represent the intervals of confidences at 0.95. CAT_A: Category of vigorous plantlets (size $\geq 4.2 \mathrm{~cm}$ ) with exhibited pores and well-open leaves; CAT_B: Category of vigorous plantlets (size $\geq 4.2 \mathrm{~cm}$ ) with exhibited pores and semi-open leaves; CAT_C: Category of vigorous plantlets (size $\geq 4.2 \mathrm{~cm}$ ) with erected pores and semi-open leaves; CAT_D: Category of no vigorous plantlets (size: 2.2 $4.1 \mathrm{~cm}$ ) with exhibited pores and well-open leaves; CAT_E: Category of vigorous plantlets (size $\geq 4.2 \mathrm{~cm}$ ) with exhibited pores and semi-open leaves; CAT_F: Category of small plantlets (size $\leq 2.1 \mathrm{~cm}$ ) with exhibited pores and semi-open leaves.

Figure 8. Number of roots issued in each category of plantlets.

Table 5. Fisher's LSD test significant differences between categories in size gain.

LSD test; difference variable

Probabilities for Post Hockey Tests

Error: $\mathrm{MC}$ Inter $=1.7824, \mathrm{dl}=66.000$

\begin{tabular}{ccccccc}
\hline Categories & $\{\mathrm{A}\}$ & $\{\mathrm{B}\}$ & $\{\mathrm{C}\}$ & $\{\mathrm{D}\}$ & $\{\mathrm{E}\}$ & $\{\mathrm{F}\}$ \\
& 2.2167 & $\mathbf{0 . 1 5 0 0 0}$ & 3.9667 & 3.7167 & 1.4000 & 1.4667 \\
\hline CAT_A & & 0.000 & 0.002 & 0.008 & 0.139 & 0.173 \\
CAT_B & 0.000 & & 0.000 & 0.000 & 0.025 & 0.018 \\
CAT_C & 0.002 & 0.000 & & 0.648 & 0.000 & 0.000 \\
CAT_D & 0.008 & 0.000 & 0.648 & & 0.000 & 0.000 \\
CAT_E & 0.139 & 0.025 & 0.000 & 0.000 & & 0.903 \\
CAT_F & 0.173 & 0.018 & 0.000 & 0.000 & 0.903 &
\end{tabular}

0.0000 ) on the category of plantlets (Table 5). For the size gain parameter, there was no difference between categories A, E and F. Indeed, the plantlets of category $B$ were represented as the one where the plants almost did not grow $(\approx 0.2 \mathrm{~cm}$ on average). The categories $\mathrm{E}$ and $\mathrm{F}$ showed an average development of $1.5 \mathrm{~cm}$ whereas those of category A got development average of $2.2 \mathrm{~cm}$. The best devel- 
opment rates were recorded in categories $\mathrm{C}$ and $\mathrm{D}$, which showed respective development average of $4 \mathrm{~cm}$ and $3.8 \mathrm{~cm}$ during the 60 days spent in the acclimatization (Figure 9).

\subsection{Weight Gain in Different Categories of Plantlets}

Figure 10 showed that the weight gain varied significantly $(P=0.0000)$ across categories of plantlets. Categories A, C, E and F had average weight gain of $0.5 \mathrm{~g}$, $1 \mathrm{~g}, 0.3 \mathrm{~g}$ and $0.2 \mathrm{~g}$ respectively. The highest rate $(1.6 \mathrm{~g})$ of weight gain was recorded in category D. In contrast, category $\mathrm{F}$ had the lowest rate of weight gain. The fresh matter gain in the categories A, C, E, and F did not differed significantly from each other but there were a significant difference between the category $\mathrm{B}(\mathrm{P}=0.001)$ and the category $\mathrm{D}(\mathrm{P}=0.000)$. All categories of plantlets were significantly different from the category $\mathrm{D}$, which had the best rate of weight gain (Table 6).

\section{Discussion}

Acclimatization is a crucial step prior to transplantation of plantlets into the field. Regarding to the pineapple, many factors need to be control for the success of this process. Recent reports focusing on extrinsic factors such as the type of

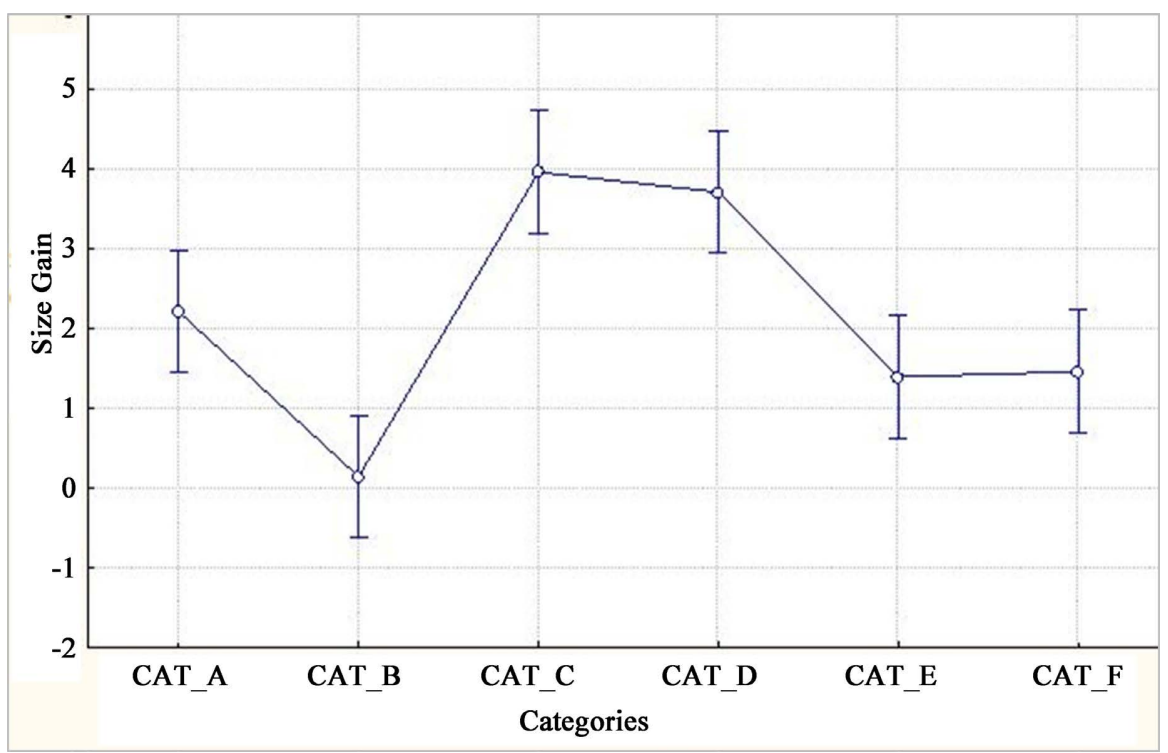

Categories; Avg. Least squares; Current effect: F (5.66) = 13.879, p = 0.00000; Effective decomposition of the hypothesis; the vertical bars represent the intervals of confidences at 0.95. CAT_A: Category of vigorous plantlets $($ size $\geq 4.2 \mathrm{~cm}$ ) with exhibited pores and well-open leaves; CAT_B: Category of vigorous plantlets (size $\geq 4.2 \mathrm{~cm}$ ) with exhibited pores and semi-open leaves; CAT_C: Category of vigorous plantlets (size $\geq 4.2 \mathrm{~cm}$ ) with erected pores and semi-open leaves; CAT_D: Category of no vigorous plantlets (size: 2.2 $4.1 \mathrm{~cm}$ ) with exhibited pores and well-open leaves; CAT_E: Category of vigorous plantlets (size $\geq 4.2 \mathrm{~cm}$ ) with exhibited pores and semi-open leaves; CAT_F: Category of small plantlets (size $\leq 2.1 \mathrm{~cm}$ ) with exhibited pores and semi-open leaves.

Figure 9. Gain in size in different categories of plantlets. 
Table 6. File LSD test on weight gain between the categories of plantlets.

LSD test; difference variable

Probabilities for Post Hockey Tests

Error: $\mathrm{MC}$ Inter $=0.37891, \mathrm{dl}=66.000$

\begin{tabular}{ccccccc}
\hline categories & $\{\mathrm{A}\}$ & $\{\mathrm{B}\}-$ & $\{\mathrm{C}\}$ & $\{\mathrm{D}\}$ & $\{\mathrm{E}\}$ & $\{\mathrm{F}\}$ \\
& $\mathbf{0 . 5 1 6 6 7}$ & $\mathbf{0 . 3 1 6 7}$ & $\mathbf{1 . 0 0 8 3}$ & $\mathbf{1 . 6 0 0 0}$ & $\mathbf{0 . 3 4 1 6 7}$ & $\mathbf{0 . 1 8 3 3 3}$ \\
\hline CAT_A & & 0.001 & 0.055 & 0.000 & 0.489 & 0.189 \\
CAT_B & 0.001 & & 0.000 & 0.000 & 0.011 & 0.051 \\
CAT_C & 0.055 & 0.000 & & 0.022 & 0.010 & 0.002 \\
CAT_D & 0.000 & 0.000 & 0.022 & & 0.000 & 0.000 \\
CAT_E & 0.489 & 0.011 & 0.010 & 0.000 & & 0.531 \\
CAT_6 & 0.189 & 0.051 & 0.002 & 0.000 & 0.531 &
\end{tabular}

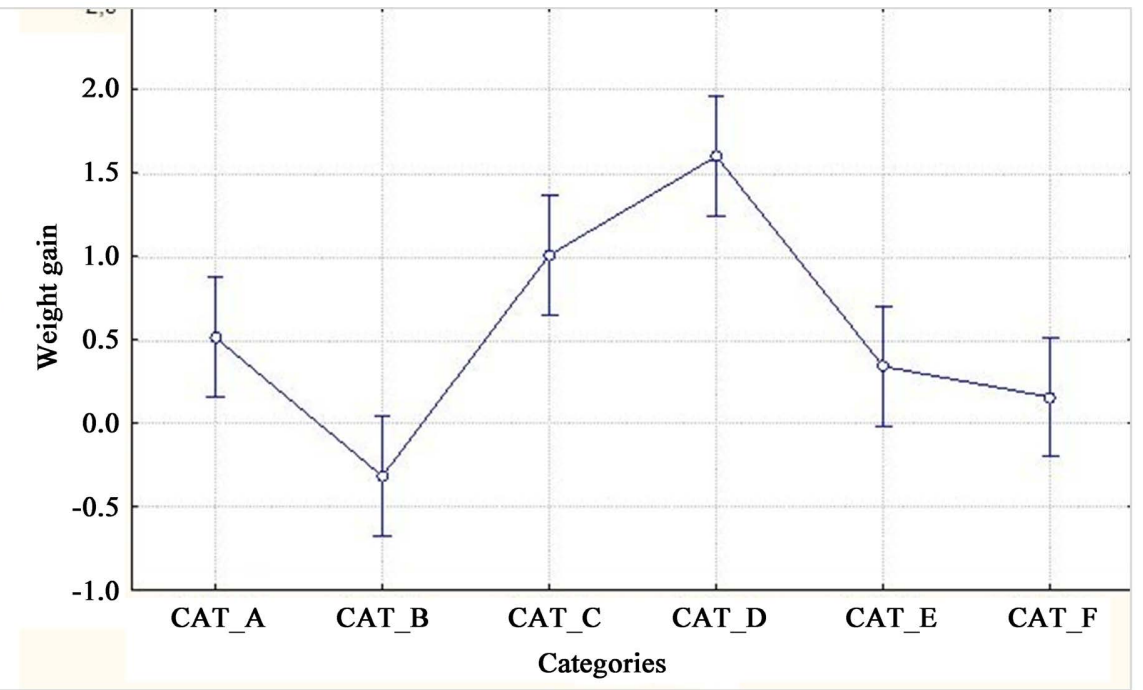

Categories; Avg. Least squares; Current effect: F (5.66) = 13.879, p = 0.00000; Effective decomposition of the hypothesis; the vertical bars represent the intervals of confidences at 0.95. CAT_A: Category of vigorous plantlets $($ size $\geq 4.2 \mathrm{~cm}$ ) with exhibited pores and well-open leaves; CAT_B: Category of vigorous plantlets (size $\geq 4.2 \mathrm{~cm}$ ) with exhibited pores and semi-open leaves; CAT_C: Category of vigorous plantlets (size $\geq 4.2 \mathrm{~cm}$ ) with erected pores and semi-open leaves; CAT_D: Category of no vigorous plantlets (size: 2.2 $4.1 \mathrm{~cm}$ ) with exhibited pores and well-open leaves; CAT_E: Category of vigorous plantlets (size $\geq 4.2 \mathrm{~cm}$ ) with exhibited pores and semi-open leaves; CAT_F: Category of small plantlets (size $\leq 2.1 \mathrm{~cm}$ ) with exhibited pores and semi-open leaves.

Figure 10. Gain of fresh material according to the different categories.

substrates and polybags showed the influence of those factors on the increasing of survival rate in the greenhouse [21]. Here, we determine how intrinsic factors and nutrient supply could influence the behavior of pineapple (smooth Cayenne cultivar) plantlets during the greenhouse acclimatization process. Two irrigation solutions, Shive and Robbins nutrient solution and NPK 14-6-5 foliar fertilizer solution were used for watering different category of plantlets. The best perfor- 
mance was observed with the Shive and Robbins nutrient solution. The foliar fertilizer being also a nutritive solution that should normally promote foliar growth, the contrary caused the fanaticism of the plantlets. By comparing the elements contained in the both solutions, it was found that apart from nitrogen, phosphorus and potassium, both solutions contained the microelements. Some authors [26] underlined the importance of nitrogen and potassium in pineapple growth. According to CIRAD [27], nitrogen is one of the elements that determine pineapple growth and yield. It determines the speed of growth and therefore the volume of the plant and the weight of the fruit [28]. Although, pineapple has a good absorption capacity in phosphorus, its need is limited [29]. The high mortality rate observed after the application of the foliar fertilizer solution was due to the high concentration of NPK becoming toxic for the fragile plantlets. Indeed, a comparative study of the composition of the two watering solutions showed that the foliar fertilizer was highly concentrated in nitrogen, phosphorus and potassium than the Shive and Robbins solution. Moreover, the nature of the molecules containing in these chemical elements was a factor that can affect their assimilation by the plantlets. Thus, it could be envisaged that at this early stage of adaptation of plantlets to the purely autotrophic mode, the combinations of the molecules contained in the Shive and Robbins nutrient solution were easier to assimilate than those contained in the foliar fertilizer solution. Also, the absorption levels of these nutrients could be questioned. Indeed, foliar fertilizer was intended to be assimilated at the leaf level. However the leaves of plantlets had their stomata constantly open, which predestine them to a high evapotranspiration that could negatively impact the availability of nutrients for their assimilation.

With regard to the behavior of the different categories of plantlets tested, it was noted that vigorous plantlets with exhibited pores and well-open leaves and vigorous plantlets with exhibited pores and semi-open leaves showed the best responses for the factors studied (survival rate, root system development, foliar emission rate and plant length growth). The foliar emission rates (0.97 and 1.22 leaves/week on average) presented by these categories of plantlets were higher compared to Folliot and Marchal [30] finding, who reported that the best foliar emission rate was 0.7 and 0.5 leaves/week on average. The similar results were obtained for the average small leaves plantlets with exhibited pore $(0.58$ leaves/week). The negative values of the foliar emission rate observed at the level of the erected pore plantlets ( -0.35 leaves/week) might be related to their fragility or hypersensitivity to the average hygrometry $(70.2 \%)$ and average temperature $\left(29^{\circ} \mathrm{C}\right)$ recorded in the greenhouse during the experiment. Indeed, several studies had already shown that for a better recovery of the plantlets in acclimatization, the relative humidity should be between $80 \%$ and $90 \%$ and the temperature between $25^{\circ} \mathrm{C}$ and $26^{\circ} \mathrm{C}$ [10] [31]. These constants limit the strong evapotranspiration observed with plantlets and favor their better recovery. In addition, plantlets with erected pores were difficult to acclimatize because they showed a 
progressive drying out from the basal of shoot to the apical zone. This justified the virtual absence of roots on these plantlets at the end of the acclimatization process. This work can be justified with the work of Konan et al., [32] on oil palm that showed a good quality of the roots produced in vitro contributes to the success of the acclimatization process. Moreover, Fki et al., [33] reported in their works on palm tree that the plantlets that have difficulty for adaptation to natural conditions were those characterized by a poor junction between the root and the aerial part. In terms of the number of roots formed and weight gain, vigorous plantlets with exhibited pores and semi-open leaves were the most successful. These results were congruent with the findings reported by [30] who stated that the heaviest plants also have the most developed root system. Further study is essential to evaluate other conditions in the greenhouse in order to optimize the acclimatization performance of the erected pore plantlets.

\section{Conclusion}

Through this study, it is established that Shive and Robbins nutrient solution gave better survival rate and growth performance of plantlets than the foliar fertilizer solution. It can be recommended as the watering solution in the earlier stage of plantlets during acclimatization. Also, the plantlets morphology affects the survival rate. Plantlets with exhibited pores with characteristics such as a number of leaves between 9 and 11, a weight between 1.2 and $1.5 \mathrm{~g}$, a size between 4.5 and $5.5 \mathrm{~cm}$ and good root system gave the highest survival rate.

\section{Acknowledgements}

This work was financially supported by the World Bank-funded ProCAD Programme. The authors acknowledge the workers of Agricultural Research Center at Niaouli station for their technical assistance.

\section{Conflicts of Interest}

The authors declare no conflicts of interest regarding the publication of this paper.

\section{References}

[1] Loeillet, D. (2005) Cyclope 2005: Les marchés mondiaux. Economica, Paris, 339-341.

[2] FAOSTAT (Food and Agriculture Organization Corporate Statistical Database) (2021) 2019 Food and Agricultural Organization-statistical Database, Recorded Data for Pineapples Production Quantity in Benin. FAO (Food and Agriculture Organization of the United Nations), Rome. http://www.fao.org/faostat/en/\#data/QC

[3] Mangara, A., N'da Adopo, A.A., Traore, K., Kehe, M., Soro, K. and Toure, M. (2010) Phytoecological Study of Weeds in Pineapple Crops. Journal of Applied Biosciences, 36, 2367-2382.

[4] Helvetas-Benin (2008) Support to the Organic and Fair Trade Pineapple Sector: 
Project Document. Helvetas-Benin, Cotonou, 120 p.

[5] Fassinou Hotegni, V.N., Lommen, W.J.M., van der Vorst, J.G., Agbossou, E.K. and Struik, P.C. (2014) Bottlenecks and Opportunities for Quality Improvement in Fresh Pineapple Supply Chains in Benin. International Food and Agribusiness Management Review, 17, 139-170.

[6] Agbangba, C.E. (2008) Contribution to the Formulation of Specific Fertilizers for Pineapple Cultivation through Foliar Diagnosis in the Commune of Allada. Thesis of Agricultural Engineer. Faculty of Agronomy, University of Parakou, Benin, 159 p.

[7] Fassinou Hotegni, V.N., Lommen, W.J.M., van der Vorst, J.G., Agbossou, E.K. and Struik, P.C. (2012) Analysis of Pineapple Production Systems in Benin. Acta Horticulturae, 928, 47-58. https://doi.org/10.17660/ActaHortic.2012.928.4

[8] Azonkpin, S., Chougourou, C.D. and Soumanou, M.M. (2017) Characteristics of the Technical Itineraries of Pineapple (Ananas comosus var. comosus) Production among Small Producers in the Commune of Allada in Benin. Annales de IUniversité de Parakou. Série «Sciences Naturelles et Agronomie», 7, 130-137.

[9] Tossou, C.C., Capo-Chichi, D.B.E. and Yedomonhan, H. (2015). Diversity and Morphological Characterization of Pineapple Varieties (Ananas comosus (L.) Merrill) Grown in Benin. Journal of Applied Biosciences, 87, 8113-8120.

https://doi.org/10.4314/jab.v87i1.2

[10] Badou, T.B., Pita, S.J., Houedjissin, S.S. and Ahanhanzo, C. (2018) Control of Endogenous Germs by Use of Antimicrobial Agents and Response of Different Explants during the in Vitro Initiation Phase of Pineapple (Ananas comosus (L.) Mill var. Comosus). Journal of Applied Biosciences, 121, 12129-12143.

https://doi.org/10.4314/jab.v121i1.4

[11] Escalona, M., Lorenzo, J.C., González, B., Daquinta, M., Borroto, C., González, J.L. and Desjardines, Y. (1999) Pineapple (Ananas comosus L. Merr) Micropropagation in Temporary Immersion Systems. Plant Cell Reports, 18, 743-748. https://doi.org/10.1007/s002990050653

[12] Daquinta, M. and Benegas, R. (1997) Brief Review of Tissue Culture of Pineapple. Pineap News, 3, 7-9.

[13] Botella, J. and Fairbairn, D. (2005) Present and Future Potential of Pineapple Biotechnology. Acta Horticulturae, 622, 23-28. https://doi.org/10.17660/ActaHortic.2005.666.1

[14] Wang, M.L., Uruu, G., Xiong, L., He, X., Nagai C., Cheah, K., Hu, J., Nan, G.L., Sipes. B. and Atkinson, H. (2009) Production of Transgenic Pineapple (Ananas comosus (L.) Merr.) Plants via Adventitious Bud Regeneration. In Vitro Cellular \& Developmental Biology-Plant, 45, 112-121.

https://doi.org/10.1007/s11627-009-9208-8

[15] Loyola-González, O., Medina-Pérez, M.A., Hernández-Ta-mayo, D., Monroy, R., Carrasco-Ochoa, J.A. and García-Borroto, M.A. (2019) Pattern-Based Approach for Detecting Pneumatic Fail-Ures on Temporary Immersion Bioreactors. Sensors, 19, Article No. 414. https://doi.org/10.3390/s19020414

[16] Parveen, S., Mir, H., Ranjan, T., Pal, A.K. and Kundu, M. (2019) Effect of Surface Sterilants on in Vitro Establishment of Pineapple (Ananas comosus (L.) Merill.) cv. Kew. Current Journal of Applied Science and Technology, 33, 1-6. https://doi.org/10.9734/cjast/2019/v33i230050

[17] Venâncio, J.B., Araújo, W.F. and Chagas, E.A. (2019) Acclimatization of Micropro- 
pagated Seedlings of Pineapple Cultivars on Organic Substrates. Científica, 47, 52-61. https://doi.org/10.15361/1984-5529.2019v47n1p52-61

[18] Yanes-Paz, E., González, J. and Sánchez, R. (2000) A Technology of Acclimatization of Pineapple Vitroplants. Pineap News, 7, 5-6.

[19] González, R., Laudat, T., Arzola, M., Méndez, R., Marrero, P., Pulido L., Dibut B. and Lorenzo, J.C. (2010) Effect of Azotobacter chroococcum on in Vitro Pineapple Plants' Growth during Acclimatization. In Vitro Cellular \& Developmental Biology-Plant, 47, 387-390. https://doi.org/10.1007/s11627-010-9334-3

[20] Soto, G., Lorente, G., Mendoza, J., Báez, E.D., Lorenzo, C.M., Rodríguez, R., Hajari, E., Vicente, O., Lorenzo, J.C. and Baez, E. (2020) Growth of Pineapple Plantlets during Acclimatization Can Be Monitored through Automated Image Analysis of the Canopy. The Euro Biotech Journal, 4, 223-229.

https://doi.org/10.2478/ebtj-2020-0026

[21] Mengesha, A., Ayenew, B. and Tadesse, T. (2013) Acclimatization of in Vitro Propagated Pineapple (Ananas comosus (L.), var. Smooth cayenne) Plantlets to ex Vitro Condition in Ethiopia. American Journal of Plant Sciences, 4, 317-323.

https://doi.org/10.4236/ajps.2013.42042

[22] Rodríguez-Escriba, R.C., Rodríguez, R., López, D., Lorente, G.Y., Pino, Y., Aragón, C.E., Garza, Y., Podestá, F.E. and González-Olme-do, J.L. (2015) High Light Intensity Increases the CAM Expression in "MD-2" Micro-Propagated Pineapple Plants at the End of the Acclimatization Stage. American Journal of Plant Sciences, 6, 3109-3118. https://doi.org/10.4236/ajps.2015.619303

[23] Lorente-González, G.Y., Pino-Legrat, Y., Rodríguez-Escriba, R.C., Pérez-Borroto, L.S., Nápoles-Borrero, L., Mendoza-Ro-dríguez, J., Cardoso, D., Alonso A., Rodríguez Sánchez, R. and González-Olmedo, J. (2018) Foliar Fertilization of "MD-2" Pine Apple Plants (Ananas comosus var. comosus) during the Acclimatization Phase. Newsletter of the Pineapple Working Group, International Society for Horticultural Science, 25, 13-17.

[24] Badou, B.T., Agbidinoukoun, A., Cacaï, G.T.H., Dossoukpèvi, R.C. and Ahanhanzo, C. (2018) Effects of System Benzylaminopurine-Adenine Sulphate in Combination with Naphthalene Acetic on in Vitro Regeneration and Proliferation of Pineapple (Ananas comosus (L.) Mill var. comosus). American Journal of Biotechnology and Bioscience, 2, 1-15.

[25] Shive, J.W. and Robbins, W.R. (1942) Sand and Water Culture Methods Used in the Study of Plant Nutrition. In: Hewitt, E.J., Ed., Technical Communication No. 22 of the Commonwealth Bureau of Horticulture and Plantation Crops, Vol. 22, 86.

[26] Adabe, K.E., Hind, S. and Maïga, A. (2016) Production et Transformation de l'Ananas. Collection Pro-Agro: Wageningen-Pays-Bas, $44 \mathrm{p}$.

[27] The French Agricultural Research and International Cooperation Organization for Sustainable Development (CIRAD) (2018) Small Guide for Pineapple Production in French Guiana. Montpellier, 3-31.

[28] Souza da Silva, L.F. and Reinhardt, D.H. (2006) Pineapple. Embrapa Mandioca e Fruticultura, Cruz das Almas-BA, Brazil, 179-201.

[29] Padonou, G.E., Aholoukpe, H.N.S., Sossa, E.L., Saidou, A. and Amadji, G.L. (2018) Réponse de l'ananas (Ananas comosus L. Merrill) à la fertilisation minérale élémentaire sur sol ferralitique au Sud du Bénin. International Journal of Biological and Chemical Sciences, 12, 2653-2666. https://doi.org/10.4314/ijbcs.v12i6.15

[30] Folliot, M. and Marchal, J. (1990) Influence of the Culture Medium on the Growth 
Rate of Pineapple Plantlets in the Acclimatization Phase. Fruits, 45, 367-378.

[31] Houssou, V.M.C., Hounsou, B.M., Allé, C.S.Y., Houssou, S., Houssou, S.C. and Agbossou, K.E. (2016) Rainfall Variability and Impact on the Water Balance of Soils under Pineapple Cultivation in South Benin. International Journal of Innovation and Applied Studies, 15, 830-845.

[32] Konan, D., Bakayoko, A., Piba, S.C., Bitignon, B.G.A. and Trabi, F.H. (2015) Dynamisme de la structure diamétrique du peuplement ligneux des différents biotopes de la forêt classée de Yapo-Abbé, sud de la Côte d'Ivoire. Journal of Applied Biosciences, 94, 8869-8879. https://doi.org/10.4314/jab.v94i1.10

[33] Fki, L., Kiaa, W., Sahnoun, N., Bouaziz, N., Masmoudi, and Drira, N. (2010) Pilot-Scale Production of Date Palm Vitroplants: Production Schemes and Constraints Treatment. In: Date Palm Biotechnology, IRD Editions, Mar-seille, 195-214. 